\title{
Evaluation of Audit Electroconvulsive Therapy Service in Psychiatric Unit at Mosul City
}

\author{
* Salem Shehab Ahmed,"* Mohammad Salih Khalaf Alkaisy, ${ }^{* * *}$ Mahmoud Mohammed Ahmed, \\ *****Nasir Muwfaq Younis \\ * Msc nursing in ibn-seena teaching hospital, Mosul, Iraq \\ ** Psychiatrist, Head of psychiatric department in ibn-seena teaching hospital, Mosul, Iraq \\ ${ }^{* * *}$ Instructor. Community Health Nursing, University of Mosul/ College of Nursing. \\ ***** Assist.Prof, CHN, University of Mosul/ College of Nursing. Iraq \\ DOI: 10.29322/IJSRP.11.01.2021.p10960 \\ http://dx.doi.org/10.29322/IJSRP.11.01.2021.p10960
}

\begin{abstract}
Background: ECT is a procedure usually performed under general anesthesia and muscle relaxation in which modified seizures induced by the selective passage of an electrical current through the brain are used for therapeutic purposes.

Objectives: The purpose of this article is to evaluation of Audit Electroconvulsive Service in Psychiatric Unit in Ibn-Sina Teaching Hospital / Mosul City

Materials and Method: A descriptive observational design has been carried out between; 1st December 2019 tills the 15th November 2019. Purposive sample was chosen by dividing the sample into two groups: group A (is the manpower who work in psychiatric unit in ISTH including all medical and nursing staff as well as anesthetics' doctor and her assistant) (28 individual). Group B include all the patients who received ECT throughout 100 sessions (34 patients).

Results: The results indicated that there is deficient in human resources practically in nurses and the study shows that the highest percentage of ages is the age group (15-24) years were $(32.4 \%)$. The males more than females were $(55.9 \%)$. (58.8\%) of the sample were unmarried. (79.4\%) were diagnosed with schizophrenia.

Conclusion: The findings of the study are concluded that the a deficiency in the numbers of nursing staff compared with the national and international standard (especially female nurses) and inadequate training of nursing staff in the unit on administration of ECT, and in the experiences of basic life support techniques.
\end{abstract}

Index Terms- Audit Electroconvulsive, Therapy Service, Psychiatric unit.

\section{INTRODUCTION}

$\mathrm{T}$ he term audit is derived from the Latin term 'audire' which means to hear. In early days an auditor used to listen to the accounts read over by an accountant in order to check them. The original objective of auditing was to detect and prevent errors and frauds ${ }^{(1)}$.Audit is a process of critically and systematically assessing our own professional activities with the intention of improving personal performance and finally the quality. The identification of explicit audit criteria is the core feature of any systemic approach to audit. The standards set should be realistic and attainable ${ }^{(2)}$.For auditors, an important task is to detect errors or deviances in the audited issues, in auditing research; the term error is normally defined as divergence between a recorded value and the correct or true value ${ }^{(3)}$.The auditor's behavior during an audit may have an important impact on the audit's results. In particular, the auditor's behavior following the detection of an auditee's error may have important consequences for the acceptance of his findings and the implementation of his recommendations. As an audit's central benefit does not only result from detecting errors, but also from improving structures and processes ${ }^{(4)}$.ECT is a procedure usually performed under general anesthesia and muscle relaxation in which modified seizures induced by the selective passage of an electrical current through the brain are used for therapeutic purposes. ECT is most commonly prescribed for treating severe depression but may also be used for other types of serious mental illness such as mania, schizophrenia, catatonia and other neuropsychiatric conditions. Where ECT is prescribed, it should form part of a treatment plan in combination with other therapies ${ }^{(5)}$. Usually ECT is given twice a week for 3 to 6 weeks (that is, a course of 6 to 12 sessions of ECT in all). Sometimes, it is given once every 2 weeks or once a month to prevent the symptoms returning. The heart and blood pressure can be affected by ECT, but the most common problem people report after ECT is short-term or long-term memory loss, which can be very distressing ${ }^{(6)}$.Convulsive therapy was first administered early last century following studies by Ladislaus von Meduna as a method of relieving the symptoms of mental illness. In 1938 Cerletti and Bini developed the first machine to produce electrically induced seizures. This replaced chemically induced seizures and the treatment became known as 'electroshock' therapy ${ }^{(7)}$. ECT is generally a safe procedure, with a documented mortality rate of $0.002 \%$ (usually related to patients receiving brief anesthesia). Two broad side effect categories for ECT include medical problems and cognitive impairments. Common medical side effects include hyper- or hypotension, tachy or bradycardia, headache, muscle ache, and nausea (usually related to anesthesia). Less common side effects include myocardial infarction, and prolonged seizure activity (status epilepticus). The major cognitive impairments resulting from ECT include anterograde and retrograde amnesia. For many patients these cognitive impairments are mild and transient; however, for some, the side effects may be long term ${ }^{(8)}$.The important of this study no such documentation and vital statistical data about the audit of ECT in 
Iraq generally and in Mosul city specifically. It is necessary to apply such research to verify and explain this topic in ECT clinics in Iraq and to provide suggestions and recommendations depending on study results. Finally, the objective of this report was to evaluation of Audit Electroconvulsive service in Psychiatric Unit in Ibn-Sina Teaching Hospital / Mosul City

\section{MeTHODOLOGY}

\section{Design and period of the study:}

The design is a clinical descriptive observational. The study had been carried out in the period from the 1st December 2019 till the 15 th November 2019.

\section{Setting of the study:}

The study was carried out at the psychiatric unit in ISTH in Nineveh Governorate, which is considered the unique psychiatric governmental unit in the city.

\section{Sample of the study:}

Purposive sample was considered in the study (it is the only local governmental clinic in Mosul city used modified ECT, it is a part of psychiatric unit in ISTH). The sample of the study includes two subjects: First: in order to evaluate the procedure of administration of ECT all manpower affiliated in the ECT clinic in psychiatric unit in ISTH were included (all medical and nursing staff as well as anesthetics' doctor and her assistant) (28 individual). Second: Cases: all patients who receive ECT throughout (100) sessions were included (34 patients).

\section{Instrument of the study:}

The tool of the study was developed from the following sources First: ECT Accreditation Service (ECTAS), Standards for the administration of ECT, Royal College of Psychiatrists 2010 (RCP, 2010), first edition was established at 2003. Second: policy on ECT, Ministry of Health of Iraq 2010(MOH of Iraq, 2010).

The tool is composed of two parts which are checked by the investigator by direct observation:
Part 1 Descriptive data of the structure of ECT clinic: composed of seven sections (101) items which were answered by (available or not available) .

- Section one: the ECT clinic and facilities; (52) items

- Section two: staff and training; (49) items

Part 2 Patient's socio-demographic status form consists of (10) items:

Socio-demographic status, type of ECT, previous ECT sessions, and admission type.

\section{Data collection method:}

Two methods used in collection of data:-

1. The evaluation of the unit were done through using the standard, direct observational technique (interview with manpower) were use in some items, and questions answered by the head of the nurse and the unit manager, especially the information regarding numbers and qualifications of medical staff, nursing staff, administrating staff and facilities, additionally the structure and the requirement of the unit were checked. Also Patients' data were collected by interview with patients or their relatives if we cannot obtain it from the patients for any reason.

2. Direct observation to the procedure done by the manpower using standard checklist form on administration of ECT.

\section{Statistical Analysis:}

To describe and analyze the findings of the study, the statistical means used were:

1. Frequency

2. Percentage

Table (1) demographical data of manpower working in psychiatric unit

\begin{tabular}{|l|l|l|l|}
\hline \multicolumn{2}{|l|}{ Unit staff } & No. & $\%$ \\
\hline \multirow{4}{*}{ physicians } & specialists house & 6 & 53.8 \\
\cline { 2 - 4 } & $\begin{array}{l}\text { Senior } \\
\text { officers }\end{array}$ & 7 & 46.2 \\
\cline { 2 - 4 } anesthetics & Total & 13 & 100 \\
\hline \multirow{5}{*}{ nurses } & anesthetics & 1 & 50 \\
\cline { 2 - 4 } & Assistant & 1 & 50 \\
\cline { 2 - 4 } & Total & 2 & 100 \\
\hline & Secondary school & 4 & 40 \\
\cline { 2 - 4 } & Institute & 3 & 30 \\
\cline { 2 - 4 } & College and above & 3 & 30 \\
\cline { 2 - 4 } & Total & 10 & 100 \\
\hline
\end{tabular}

This table show, according to physicians; that the highest percentage was specialist $(53.8 \%)$, according to anesthetics; there is one anesthetic doctor with his assistant, and according to the nurses the highest percentage was secondary school graduates $(40 \%)$. 


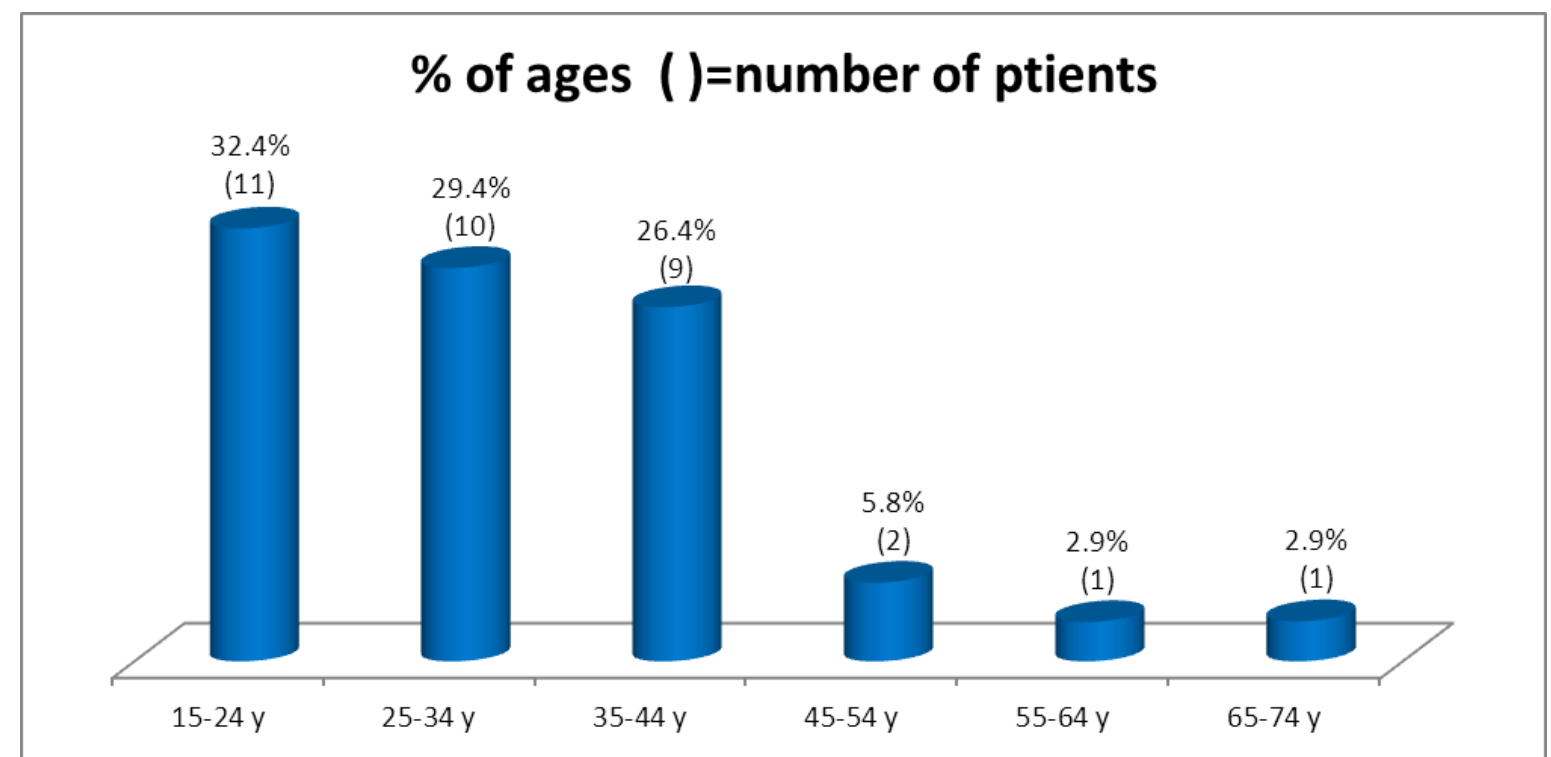

Figure (1) Ages' distribution of the patients that receive ECT during data collection period (total =34 pts.)

\section{$\%$ of patients' gender ( )=number of patients}
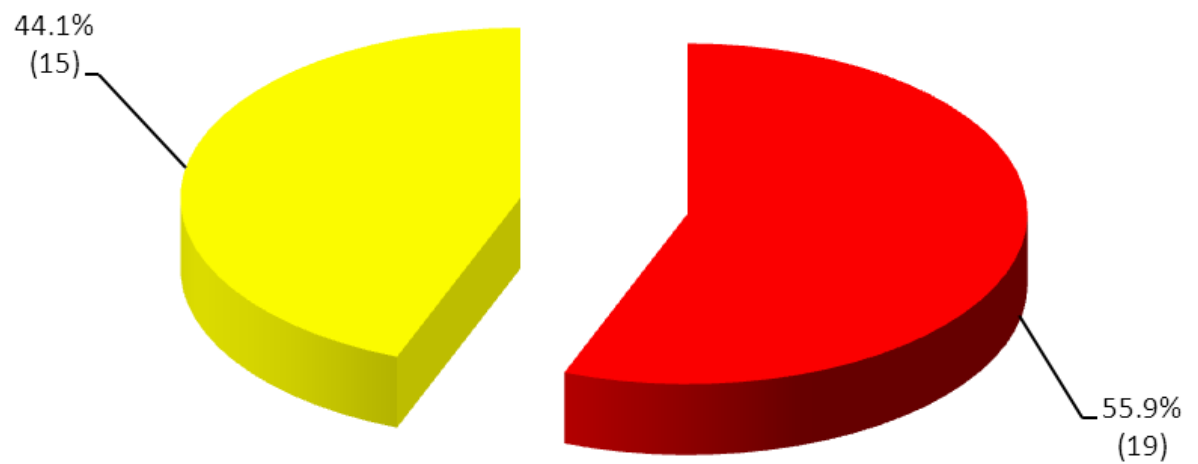

Figure (2) percentage and numbers of patients' gender that receive ECT data collection period (total =34 pts.) 


\section{$\%$ of marital stutus $\quad()=$ number of patients}

$58.8 \%$

(20)

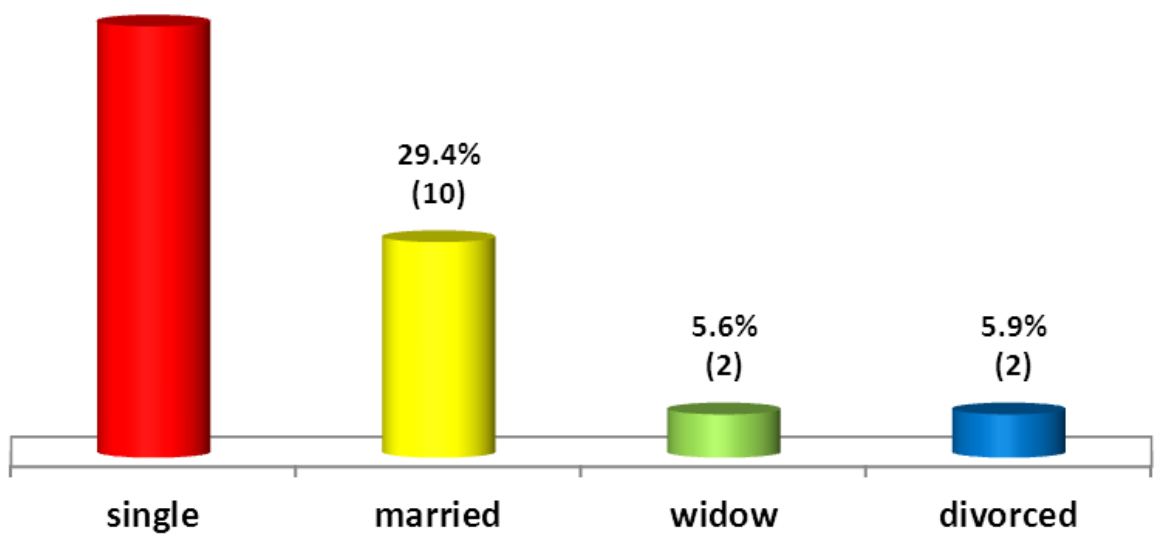

Figure (3) distribution of marital status among patients receive ECT (total =34 pts.)

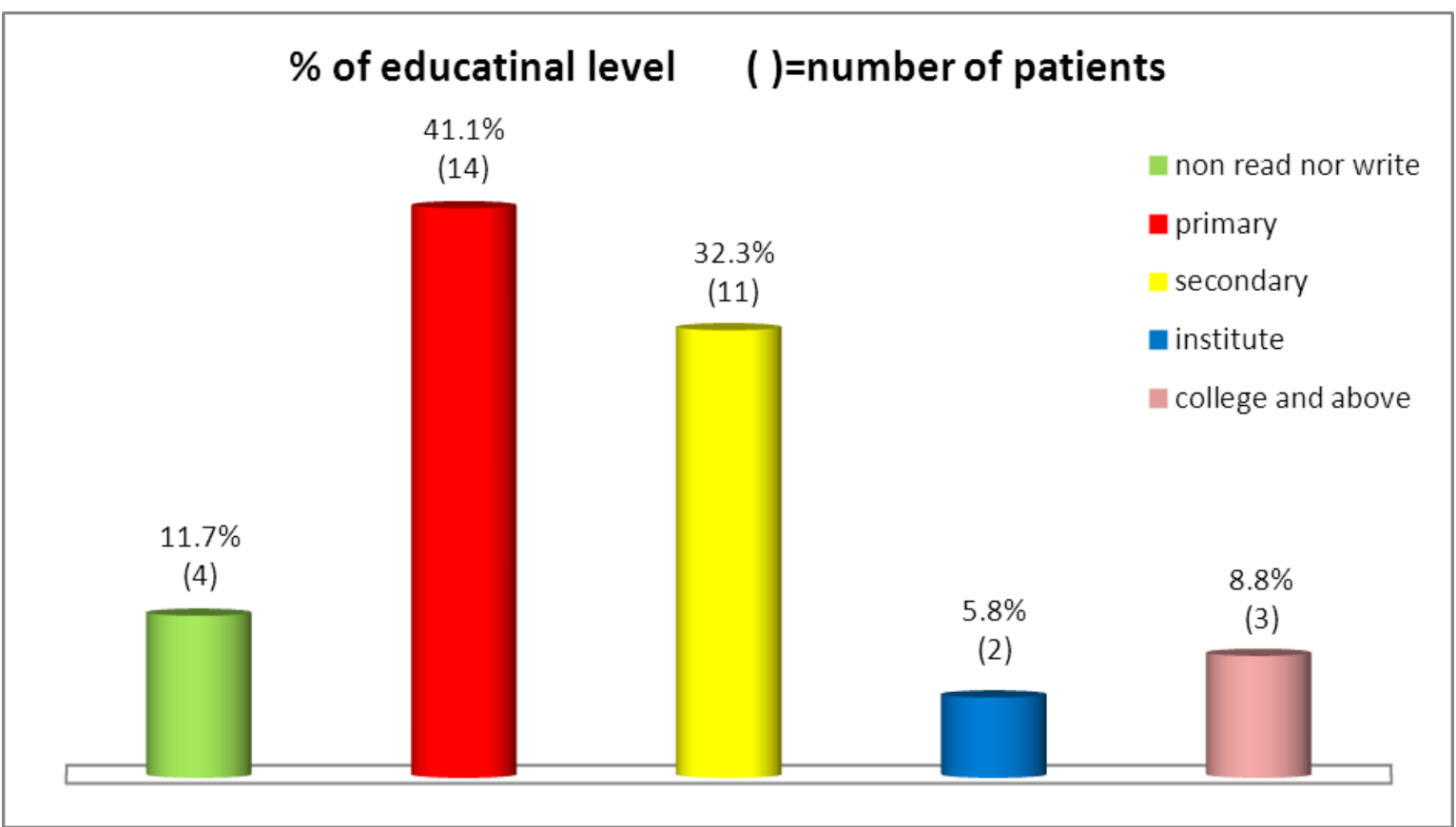

Figure (4) percentage and number of patients of educational level between patient receive ECT (total =34 pts.) 


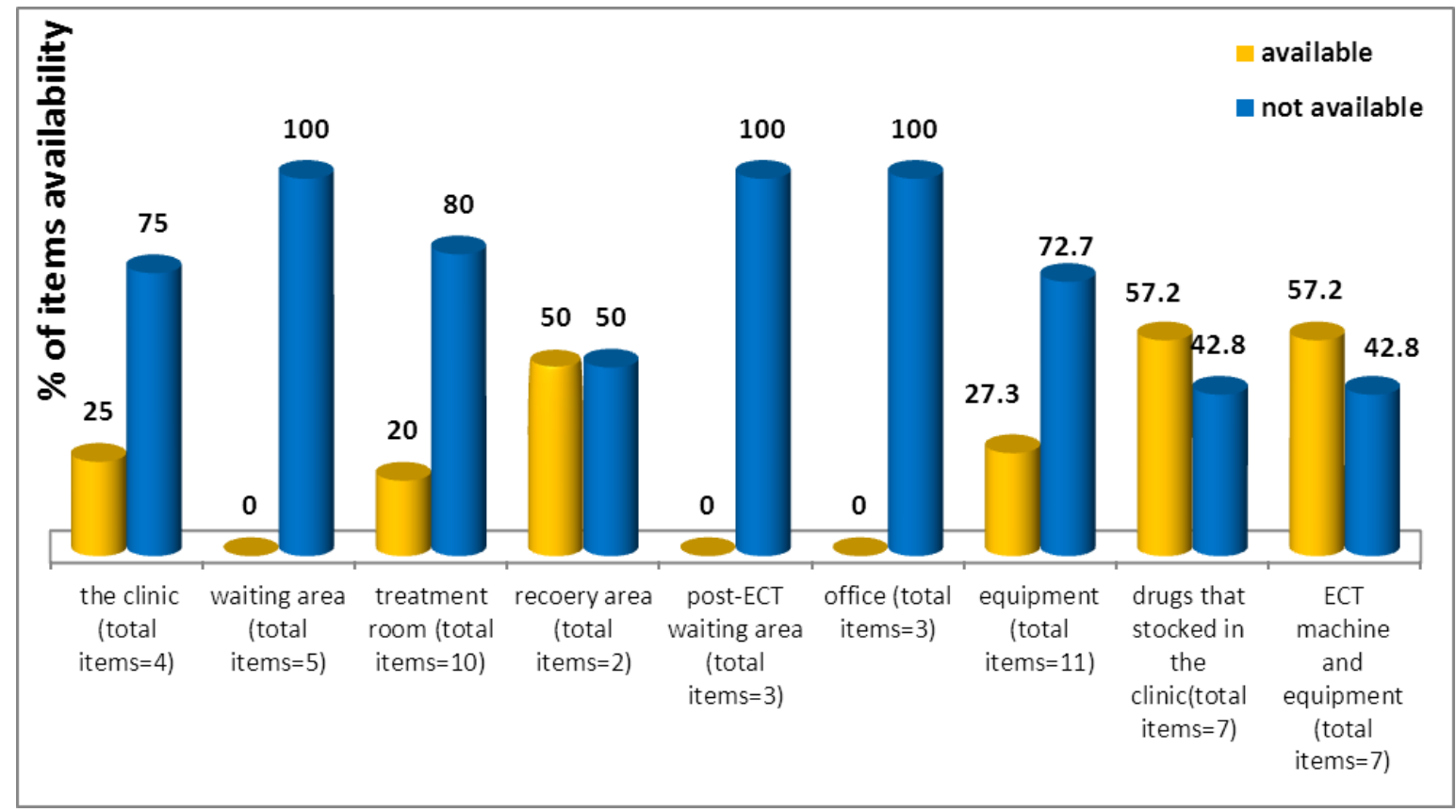

Figure (5) the clinic and facilities

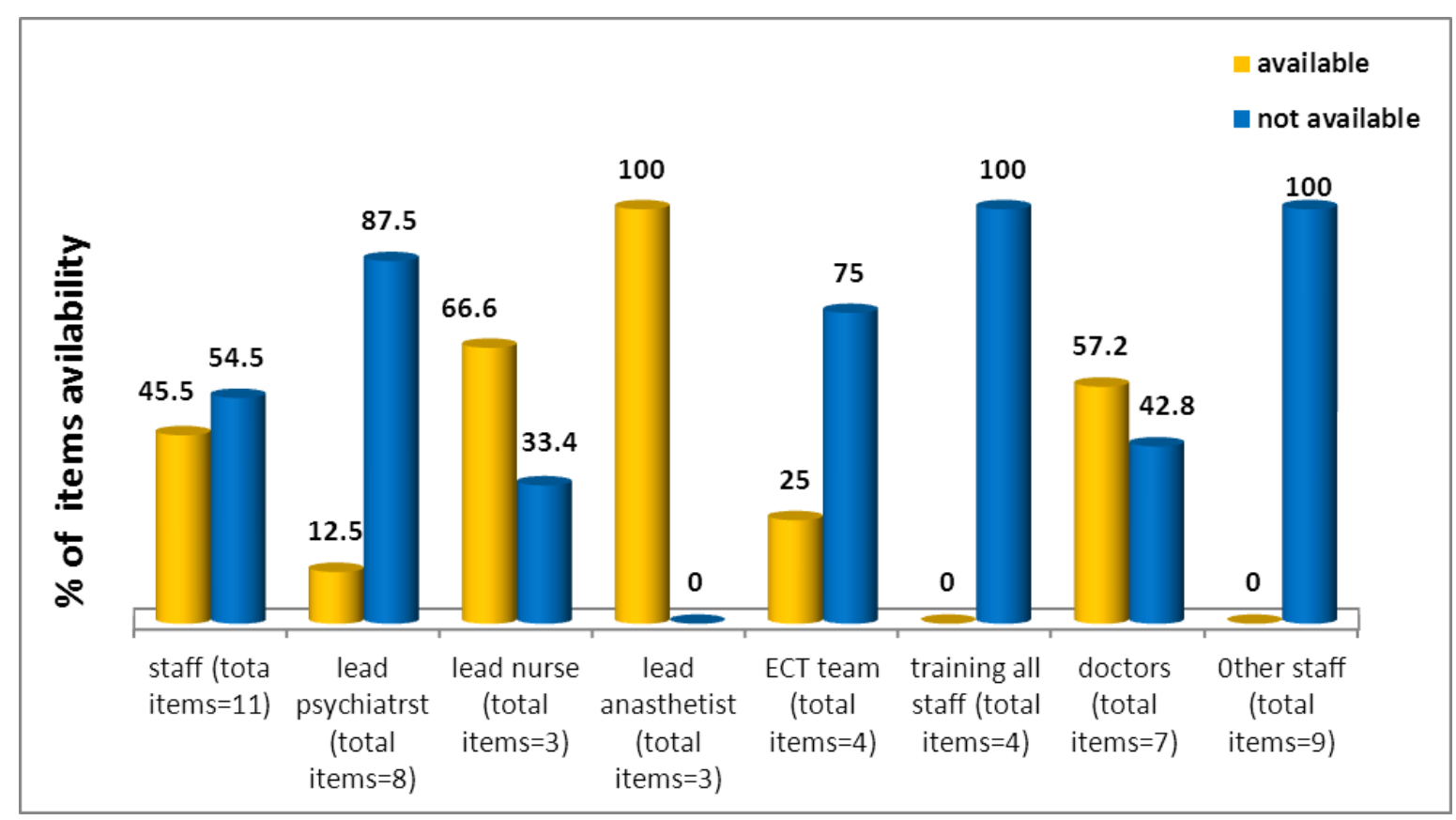

Figure (6) staff and training 


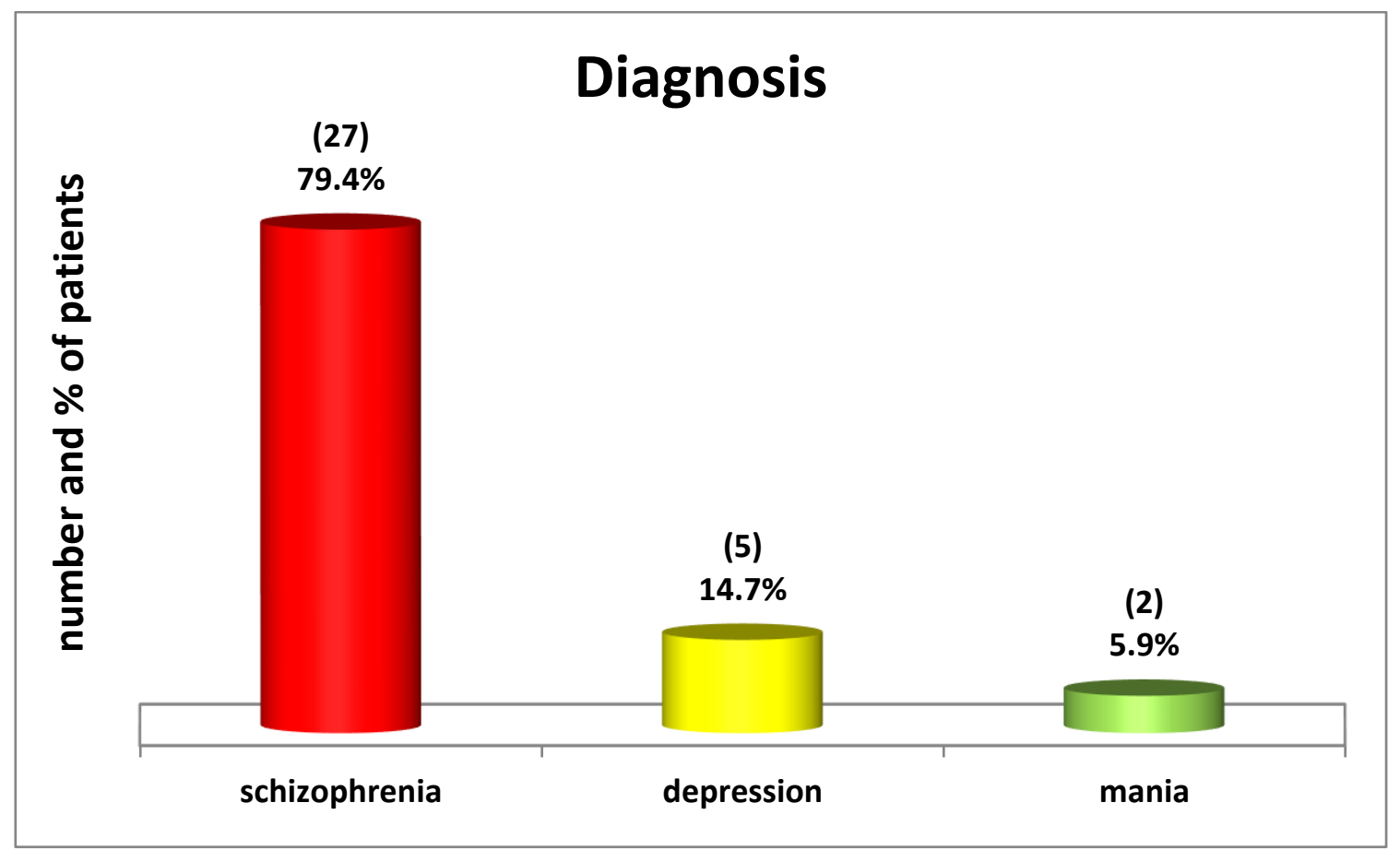

Figure (7) diagnosis of patients receive ECT during data collection period (total =34 pts.)

\section{DISCUSSION}

To audit ECT in this study the investigator will comment on the findings which reflect the local services in psychiatric unit in ISTH. As ECT unit has been recently established and equipped for modified clinic in the psychiatric unit, there will be an expected deficiency in provided services as compared to the international standard, added to the lack of training program, manpower and other resources (building and supply) due the period of wars and sanction on Iraq. The investigator will present the findings as a first step in audit before planning to remedy the defect.This study is the first in Iraq; it explains the reason for not comparing the findings with local results. Internationally still the available reports are scanty (RCP and Scottish annul audit only).This study shows that, regarding physicians, there are adequate numbers and qualifications, also the clinic has one anesthetic doctor with her assistant. As for the nurses, the total number is (10). This number represents the total nursing staff affiliated in psychiatric unit in ISTH introduce services covering day and night shifts in addition to the ECT clinic itself, therefore; mostly we observe that is only two nurses present during ECT treatment and recovery (table 1).According to RCP standard, it should be at least one trained nurse plus one experienced nurse in treatment room, with same numbers in recovery area. In addition to one person competent in cardiopulmonary resuscitation with another trained as a life support provider. When the results of this study are compared with the standard it revealed that there is a defect and lack in the nursing staff who should be caring for the patients in the treatment room and recovery area. This finding can be explained by the fact that there is a real nursing shortage in general and especially in psychiatric unit, this may be due to the negative attitudes of health care workers towards mental health sector. This study shows that the highest percentage of patients aged from (15-24) years was $32.4 \%$ (11) patients , minimum age was 16 years and maximum age was 71 , mean age was 39.5 years, and $87 \%$ of total patients was under 45 years (figure 1). The findings of this study are in accordance with: ${ }^{(9,10)}$.But it is different from the findings McKersie (2011) who stated that the average age of admission for ECT was (57.49) ${ }^{(11)}$. And finally Garg et al. (2011) indicated that $43.3 \%$ were between 26 and 35 years of age, the mean age of the patients was $31.53 \pm$ years with a range of 21 to 45 years. The difference in the findings may be due to sampling technique or the tools of assessment used in the above studies ${ }^{(12)}$. Adding these findings reflect the effect of stress on the younger generation in Iraq plus the strategy of the admission to the psychiatric unit (which is the only unit in Mosul city for acutely ill inpatients only).This study found that 19 patients $(55.9 \%)$ were males, 15 patients $(44.1 \%)$ were females (figure 2 ). The variation could be due to the different guidelines of indications and administration of ECT in different centers. This study shows that $58.8 \%$ were singles and $29.4 \%$ were married (figure 3 ). This is in agreement with the results of Garg et al. (2011) who indicated that the majority of his sample $(66.7 \%)$ was unmarried. These findings may mostly be due to the fact that the affected patients are young aged and have more chance to be affected by psychiatric illness. The findings of this study show that most of the sample 14 patients $(41.1 \%)$ who receive ECT were graduate of primary school and 11 patients $(32.3 \%)$ were graduated of secondary school (figure 4). The findings of this study show that the ECT clinic in ISTH has an adequate size of treatment room ( 25 square meters) but there is no pre ECT waiting area, these findings explain that there is only $25 \%$ of clinic structure complying with standard. Figure (6) shows that the clinic complies with $45.5 \%$ of the standard regarding staff and training: there is one suitably trained psychiatrist present during treatment, one experienced psychiatrist, and one trained nurse present in the treatment room, but there is no trained nurse in the recovery area, the clinic doesn't meet the standard of RCP in the 
recovery regarding the number of staff which must exceed the number of unconscious patients by one.

\section{CONCLUSION}

1. There is a deficiency in the numbers of nursing staff compared with the national and international standard (especially female nurses).

2. Inadequate training of nursing staff in the unit on administration of ECT, and in the experiences of basic life support techniques.

\section{RECOMMENDATION}

1.Provide ECT treatment room by the necessary equipment such as a new ECT machine that contain EEG with ECG monitoring, anesthetic machine, pulse oximetry, capnograph, means of measuring blood glucose concentration, and trolley that has braked wheels and can rapidly tipped into head down positions.

2.Provide ECT treatment room by the anesthetic induction with muscle relaxant agents continuously, and emergency tray contains drugs necessary for cardiopulmonary resuscitation.

\section{REFERENCES}

[1] Gilmore, I.; Clinical Governance: (2018).What Is It , What Isn't, And What Should Be. Hospital Medicine; 61:Pp.51-53.

[2] Andrea Benjamin; Audit:(2012) How To Do It In Practice. BMA House, London WC1H 9JR BMJ;336: 1241-5

[3] Richard Huw Davies and Rowan Wilson (2011), Audit of an electroconvulsive therapy clinic's missed-fit rate, The Psychiatrist Journal 25: 215-216.
[4] Ferris M., Challans E., Ashmore S., Johnson T.,Kuczyc R., And Hartley J.:(2015). Clinical Governance Support Team :A Practical Handbook For Clinical Audit : p.p.(3-13).

[5] Department Of Health; Terms And Conditions Of Service Of Hospital And Medical And Dental Staff, London; 2017.

[6] National Institute For Clinical Excellence(NICE) ; Principles For Best Practice In Clinical Audit; Typeset By Aaron Type Ltd, Easton, Bristol Printed And Bound By TJ International Ltd, Padstow, Cornwall UK. 2012.Pp.1-2.

[7] Dowman J., Patel A., and Rajput K.(2018). Electroconvulsive therapy: attitudes and misconceptions. Journal of ECT; 21:84-87.

[8] Grace Fergusson, James Hendry and Chris Freeman (2013), Do patients who receive electroconvulsive therapy in Scotland get better?, The Psychiatrist Journal, 27: 137-140

[9] Robert Eliot; (2015) Clinical Audit Policy: Royal United Hospital; UK. Ref.: 232 Issue Date; November. PP.9.

[10] Balogh R, Simpson A, Bond S.;(2011). Involving Clients In Clinical Audits Of Mental Health Services; Int J Qual Health Care; 7:343-53.

[11] Juanjo Solano, (2009) Electroconvulsive Therapy, School of Electrical and Electronic Engineering, University of Manchester, UK,pp.2.

[12] Craig Anderson, Peter Skegg, Ranui Wilson, Maree Hackett, Jeanne Snelling and Anisha Grover, (2004): Use Of Electroconvulsive Therapy (ECT) In New Zealand: A Review Of Efficacy, Safety, And Regulatory Controls, Ministry of Health, pp.1.

\section{AUTHORS}

First Author - Salem Shehab Ahmed, Msc nursing in ibn-seena teaching hospital, Mosul, Iraq

Second Author - Mohammad Salih Khalaf Alkaisy, Psychiatrist, Head of psychiatric department in ibn-seena teaching hospital, Mosul, Iraq

Third Author - Mahmoud Mohammed Ahmed, Instructor. Community Health Nursing, University of Mosul/ College of Nursing.

Fourth Author - Nasir Muwfaq Younis, Assist.Prof, CHN, University of Mosul/ College of Nursing. Iraq , E-mail: nasir_younse@yahoo.com 